\title{
Arterial hypertension and electrocardiographic diagnosis of left ventricular hypertension in the group of geriatric patients with coronary heart disease living in the far north
}

\author{
Natalya Arkhipova ${ }^{1}$, Elena Popova ${ }^{2}$, Aleksandr Ariev $^{3}$ \\ ${ }^{1}$ Yakutsk Science Centre of Complex Medical Problems of the Siberian Branch of the Russian Academy of Medical Science, Ya- \\ kutsk, Russia; nati8692@mail.ru \\ ${ }^{2}$ Medical Institute of the North-Eastern Federal University Named after M. K. Ammosov, Yakutsk, Russia; \\ ecapopova@yandex.ru \\ ${ }^{3}$ Saint-Petersburg Medical Academy of Postgraduate Education, St.-Petersburg, Russia; ariev_al@mail.ru
}

Received 2 April 2013; revised 3 May 2013; accepted 10 June 2013

Copyright (C) 2013 Natalya Arkhipova et al. This is an open access article distributed under the Creative Commons Attribution License, which permits unrestricted use, distribution, and reproduction in any medium, provided the original work is properly cited.

\section{ABSTRACT}

As a result of research, high prevalence of arterial hypertension has been identified in the group of patients with coronary heart disease aged 60 and older. Most often, occurring form of arterial hypertension among geriatric patients is isolated systolic arterial hypertension (ISAH). The comparison of two ethnic groups of the population has showed higher levels of systolic and diastolic blood pressure (SBP and DBP) in the group of patients of non-indigenous nationality, rather than Yakut patients. Correlation was recorded in the group of non-indigenous patients as they age. Significant increase in the level of SBP was identified in the group of senile and long-livers than in the elderly. Detection of ECG signs of LVH showed the lowest specificity of Cornell voltage criterion comparing to SokolowLyon criterion with its more often occurrence. ECG-signs of left ventricle hypertrophy are significantly more often established by SokolowLyon criterion for men, Cornell voltage-for women. Correlation has been found between the presence of LVH and combination of Cornell voltage criterion with both Gubner-Ungerleider and Sokolow-Lyon criteria.

Keywords: Arterial Hypertension; Coronary Heart Disease; Geriatric Age; Non-Indigenous and Yakut Patients; Electrocardiographic Criteria of Left Ventricle Hypertrophy

\section{INTRODUCTION}

According to the data of the World Health Organization, arterial hypertension takes the leading position in the rating of the most actual diseases on the planet. High blood pressure increases the risk of cardiovascular complacations and further can bring the rise in annual deaths: from 17 million in 2008 to 25 million in 2030 [1]. A described world epidemiological situation on arterial hypertension is similar to that in Russian Federation, where cardiovascular diseases make the greatest contribution to the total number of deaths $-56.5 \%$ in 2009 ( 1 million 137 thousand), while the proportion of arterial hypertension, as a direct cause of death, is $2.2 \%$ of all the cases [2]. For the last forty years, the mortality caused by cardiovascular diseases in Republic of Sakha (Yakutia) has risen from $15.7 \%$ to $47.5 \%$, that is first of all due to the change of the age structure of the population, its aging, as well as rejuvenation of mortality from heart diseases [3]. In 2009 high blood pressure was observed in $4.3 \%$ of the Russian Federation citizens [2]. As to the results of conducted research in 2011 in Republic Sakha region's capital, the prevalence of arterial hypertension among working-age population made up to $40 \%$ [4]. The literature data suggest that the patients already having cardiovascular events belong to the group with the highest risk [5]. In recent years the researchers are paying more attention to the regional characteristics study of cardiovascular diseases, to its outcomes, particularly of coronary heart disease and arterial hypertension. The difference in the frequency of hypertension can be seen between the natives and migrants in a number of papers, that is to say 
an association of hypertension with the ethnicity of the population (including the level of adaptation to the specific climatic and geographic regions) [6-9].

\section{AIM}

To study hypertension prevalence and detect left ventricle hypertrophy, considering nationality, age and gender, in the group of geriatric patients with CHD living in the far north.

\section{MATERIALS AND METHODS}

We included into the study 354 patients aged 60 and older with verified diagnosis of coronary heart disease. National structure of the studied population: indigenous nationality is presented by Yakut people-100\% averageage $77.6 \pm 0.6$ years), non-indigenous nationalityRussians - $91.3 \%$ and $8.7 \%$ are consisted of Ukrainians, Tatars and Germans (middle age $75.5 \pm 0.7$ years). All surveyed were divided as follows: on ethnic originnon-indigenous $(n=149)$ and indigenous $(n=205)$; on gender - men $(n=187)$ and women $(n=167)$; on ageelderly (from 60 to 74 years, $n=154$ ), senile (from 75 to 89 years, $n=149$ ) and long-livers (90 and over, $n=51$ ). Length of stay of non-indigenous patients in Yakutia was more than 30 years.

In accordance with recommendations of experts of World Health Organization and the International Society on Hypertension (1999) and Russian Society of Cardiology (2001), level of $\mathrm{AH} \geq 140 / 90 \mathrm{mmHg}$ was taken as arterial hypertension (AH), SBP or DBP of 140 - 150/90 - $99 \mathrm{mmHg}$ was accepted as I degree ofAH, SBP or DBP of 160 - 179/100 - $109 \mathrm{mmHg}$ - II degree of AH, SBP or DBP of 180/110 mmHg and more-III degree of AH. For the purpose of revealing the signs of left ventricular hypertrophy myocardium we used voltage criteria, namely, M. Sokolow, T. Lyon (1949) (Sv1 + Rv5 - v6 $\geq 35$ mm), R. Gubner, H. Ungerleider (1943) (R1 + S3 $\geq 25 \mathrm{~mm})$ and criteria of Cornell university (the Cornell amplitude parameter Ravl $+\mathrm{Sv} 3>28 \mathrm{~mm}$ for men and $>20 \mathrm{~mm}$ for women).

Thestudy was approved by local committee on biomedical ethics at Yakut scientific centre on complex medical problems of Russian Academy of Medical Sciences.

Statistical processing of the received results was obtained with the use of methods of parametric and nonparametric statistics. Methods of descriptive statistics included an estimation of the arithmetic mean (M), mean error of mean value (m) - for the signs having continuous distribution; and also frequencies of signs occurrence with discrete values. Student's $t$-test was applied to estimate intergroup differences of signs having continuous distribution. Both Pearson's chi-squared test $\left(\chi^{2}\right)$ and
Fisher's exact test were used for comparison of frequency values. Also we made use of multiple methods of intergroup differences: Kruskal-Wallis H, one-, two- and three-factor analysis of variance (ANOVA). When comparing paired samples Student's $t$-test was used. Dependence analysis between signs was done using Pearson's $r$, Spearman's rs and Pearson's $\chi^{2}$ tests. We also applied linear discriminant analysis.

Statistical processing of the material was carried out with the help of standard software package Statistica for Windows v. 6.0. Critical confidence level of null hypothesis (on absence of significant differences or factor influences) was considered to be 0.05 .

\section{RESULTS}

In the study group $(n=354)$ the level of SBP $\geq 140$ $\mathrm{mmHg}$ has been noted in all 149 non-indigenous people. Among Yakut people, taking into the account identified normal high SBP in six people $(2.9 \%)$, the level of SBP $\geq$ $140 \mathrm{mmHg}$ was observed in $199(97.1 \%)$ out of 205 surveyed $\left(\chi^{2}=2.85, p=0.091\right)$. Average age of the observed population corresponded to senile age and was authentically higher among Yakut people rather than non-indigenous population. Comparative analysis of mean systolic and diastolic blood pressure among the older age group revealed the differences depending on ethnicity. Levels of SBP and DBP in non-indigenous patients were higher than Yakut $(166.3 \pm 1.5,162.0 \pm 1.4$ $\mathrm{mmHg}$ and $84.7 \pm 0.8,82.0 \pm 0.6$ respectively) $(t=2.08$, $p=0.039$ ) (see Table 1).

Moreover, it was founded out that non-indigenous patients had dependence of SBP on age $(r=0.17, p=0.037)$ viz. the older the patient, the higher the level of blood pressure, which was not followed up in the group of Yakut patients $(r=0.06, p>0.10)$. We also revealed significant distinctions in the values of systolic blood pressure levels when comparing groups according to ageelderly, senile age and long-livers, elderly and senile age group. What is more, there was no reduction in levels of blood pressure with age and with decrease in body mass index (Table 2).

We revealed no significant difference in the levels of SBP and DBP when comparing groups of men with women $(164.3 \pm 1.4 ; 163.4 \pm 1.4, t=0.5 ; p>0.10$ и 82.6

Table 1. Comparison of age, blood pressure of geriatric patients with CHD $(n=354)$.

\begin{tabular}{ccccc}
\hline \multirow{2}{*}{ Indexes } & \multicolumn{2}{c}{ Population } & & \\
\cline { 2 - 3 } & $\begin{array}{c}\text { non-indigenous } \\
(n=149)\end{array}$ & $\begin{array}{c}\text { indigenous } \\
(n=205)\end{array}$ & & $p$ \\
\hline Age (years) & $75.5 \pm 0.7$ & $77.6 \pm 0.6$ & 2.28 & $=0.023$ \\
SBP (mmHg) & $166.3 \pm 1.5$ & $162.0 \pm 1.4$ & 2.08 & $=0.039$ \\
DBP $(\mathrm{mmHg})$ & $84.7 \pm 0.8$ & $82.0 \pm 0.6$ & 2.58 & $=0.010$ \\
\hline
\end{tabular}


Table 2. Comparison of age, body mass index, blood pressure of geriatric patients with CHD $(n=354)$.

\begin{tabular}{ccccccc}
\hline \multirow{2}{*}{ Signs } & \multicolumn{5}{c}{ Age } & \\
\cline { 2 - 4 } & $\begin{array}{c}\text { elderly } \\
(n=154)\end{array}$ & $\begin{array}{c}\text { senile } \\
(n=149)\end{array}$ & $\begin{array}{c}\text { long-livers } \\
(n=51)\end{array}$ & $H$ & $p$ \\
\hline \multirow{2}{*}{ Age } & $69.0 \pm 0.3$ & $79.6 \pm 0.3$ & $91.9 \pm 0.4$ & - & - \\
& & & & & \\
BMI $\left(\mathrm{kg} / \mathrm{m}^{2}\right)$ & $26.8 \pm 0.4$ & $26.3 \pm 0.3$ & $23.4 \pm 0.4^{1}$ & 30.60 & $<0.001$ \\
SBP $(\mathrm{mmHg})$ & $160.5 \pm 1.4^{2}$ & $166.9 \pm 1.5$ & $165.2 \pm 3.3$ & 9.92 & $=0.007$ \\
DBP $(\mathrm{mmHg})$ & $82.9 \pm 0.7$ & $83.2 \pm 0.8$ & $83.7 \pm 1.7$ & 0.11 & $>0.10$ \\
\hline
\end{tabular}

Note: ${ }^{1} t=4.79, p<0.001$ (comparison of long-livers with elderly patients); ${ }^{2} t=3.10, p=0.002$ (comparison of elderly with senile patients).

$\pm 0.7 ; 83.7 \pm 0.7, t=1.05 ; p>0.10$ respectively).

There are no statistically significant differences in degree of increase in systolic blood pressure between nonindigenous and indigenous groups of patients, butonly a slight tendency to more severe arterial hypertension in non-indigenous patients $\left(\chi^{2}=7.75, p=0.067\right)$.

Isolated systolic hypertension was the most often occurring form of $\mathrm{AH}$ among geriatric patients in the surveyed group. The level of DBP was higher in patients of non-indigenous nationality. The difference between two groups of population becomes more obvious while assessing the degree of AH in view of SBP and DBP value. The proportion of patients having DBP $90 \mathrm{mmHg}$ or higher was more significant in the group of non-indigenous nationality $\left(\chi^{2}=5.57, p=0.018\right)$ (Table 3 ).

Arterial hypertension brings to organ damages and in order to identify one of them-left ventricular hypertrophy (LVH) - we used the method of ECG.

For the diagnosis of LVH were used traditional (most frequently used) ECG criteria for LVH (Sokolow-Lyon, Cornell voltage and Huebner-Ungerleider).

In each of three age groups ECG signs of LVH were most often identified by Cornell voltage criterion and very rarely set by Huebner-Ungerleider criterion. There were no significant differences in the frequency of occurrence of the ECG criteria for LVH (each separately) when comparing the groups by nationality. However, when it comes to comparison of the ECG criteria with each other, there was significantly more frequent definition of LVH signs while using the ECG criteria Cornell voltage rather than two other criteria-Sokolow-Lyon $\left(\chi^{2}\right.$ $=27.98, p<0.001)$ and Huebner-Ungerleider $\left(\chi^{2}=\right.$ 107.79, $p<0.001$ ) (Table 4).

There were found no great differences in the frequency of detection of ECG-criteria between three age groups. Comparison of two groups by gender showed the following: men had ECG-signs of LVH more often than women did using Sokolow-Lyon criterion, while woman had ECG-signs of LVH more often compared with men
Table 3. Frequency of detection of isolated systolic hypertension and increased diastolic blood pressure in non-indigenous and indigenous geriatric population with coronary heart disease $(n=354)$.

\begin{tabular}{|c|c|c|c|c|c|c|}
\hline \multirow{3}{*}{$\begin{array}{c}\text { Categories of blood } \\
\text { pressure } \\
\text { (Considering SBP and } \\
\text { DBP mmHg) }\end{array}$} & \multicolumn{4}{|c|}{ Population } & \multirow{3}{*}{$\chi^{2}$} & \multirow{3}{*}{$p$} \\
\hline & \multicolumn{2}{|c|}{$\begin{array}{l}\text { non-indigenous } \\
\quad(n=149)\end{array}$} & \multicolumn{2}{|c|}{$\begin{array}{l}\text { indigenous } \\
(n=205)\end{array}$} & & \\
\hline & abs. & rel. \% & abs. & rel. $\%$ & & \\
\hline $\begin{array}{c}\text { Isolated systolic } \\
\text { hypertensions } \\
(\mathrm{SBP} \geq 140, \mathrm{DBP}<90)\end{array}$ & 94 & 63.1 & 150 & 73.2 & 5.57 & $=0.018$ \\
\hline $\mathrm{DBP} \geq 90$ & 55 & 36.9 & 49 & 23.9 & & \\
\hline
\end{tabular}

Table 4. Frequency of different parameters of LVH presencein non-indigenous and Yakut patients with CHD (354) according to the ECG data.

\begin{tabular}{cccccccc}
\hline \multirow{4}{*}{\begin{tabular}{c} 
Indexes \\
\cline { 2 - 5 } (ECG LVH criteria) $)$
\end{tabular}} & $\begin{array}{c}\text { non-indigenous } \\
(n=149)\end{array}$ & \multicolumn{2}{c}{$\begin{array}{c}\text { indigenous } \\
(n=205)\end{array}$} & \multirow{2}{*}{$\chi^{2}$} & $p$ \\
\cline { 2 - 5 } & abs. & rel. \% & abs. & rel. \% & & \\
\hline Sokolow-Lyon & 17 & 11.4 & 37 & 18.0 & 2.45 & $>0.10$ \\
Cornell voltage & 47 & 31.5 & 68 & 33.2 & 0.04 & $>0.10$ \\
Huebner-Ungerleider & 5 & 3.4 & 4 & 2.0 & 0.24 & $>0.10$ \\
\hline
\end{tabular}

Note: Cornell voltage criterion against Sokolow-Lyon $\left(\chi^{2}=27.98, p<0.001\right)$ and Huebner-Ungerleider criteria $\left(\chi^{2}=107.79, p<0.001\right)$.

using Cornell voltage criterion (Table 5).

In addition to determining the frequency of occurrence of ECG-criteria for LVH, we considered their combination with the purpose of comparing informational content of examined ECG criteria separately as well as their combination for LVH diagnostic. Analysis of the combination of ECG criteria Sokolow-Lyon and Cornell voltage is presented in Table 6.

Thirty one was a number of patients who had coincidence in the results from the use of two criteria-Sokolow-Lyon and Cornell voltage. Based on ECG analyses of 354 patients with CHD aged 60 and older there was revealed coincidence in 31 patients in the results from the use ofSokolow-Lyon and Cornell voltage criteria.

Separately Sokolow-Lyon and Cornell voltage criteria were found in 66 and 124 (out of 354) people accordingly. With a combination of these two criteria the presence of LVH signs was confirmed by Sokolow-Lyon criterion in $47.0 \%$ of cases, by Cornell voltagecriterion only in $25.0 \%$, despite the fact that it registered almost two times more often than Sokolow-Lyon criterion. 35 out of 66 people, who had registered sign of left ventricle hypertrophy when using Sokolow-Lyon criterion, did not have any coincidence with Cornell voltage criterion. More discrepancies were recorded in patients with ECG signs of LVH by Cornell voltage criterion, specifically, in $93(26.3 \% ; n=354)$ out of 124 patients. Having com- 
Table 5. Frequency of different parameters of LVH presence in men and women of both non-indigenous and indigenous nationality with CHD (354) according to the ECG data.

\begin{tabular}{|c|c|c|c|c|c|c|}
\hline \multirow{3}{*}{$\begin{array}{c}\text { Indexes } \\
\text { (ECG LVH criteria) }\end{array}$} & \multicolumn{4}{|c|}{ Gender } & \multirow{3}{*}{$\chi^{2}$} & \multirow{3}{*}{$p$} \\
\hline & \multicolumn{2}{|c|}{$\begin{array}{c}\text { men } \\
(n=187)\end{array}$} & \multicolumn{2}{|c|}{$\begin{array}{l}\text { women } \\
(n=167)\end{array}$} & & \\
\hline & abs. & rel. \% & abs. & rel. \% & & \\
\hline Sokolow-Lyon & 36 & 19.3 & 18 & 10.8 & 4.27 & $=0.039$ \\
\hline Cornell voltage & 39 & 20.9 & 76 & 45.5 & 23.34 & $<0.001$ \\
\hline Huebner-Ungerleider & 7 & 3.7 & 2 & 1.2 & 1.39 & $>0.10$ \\
\hline
\end{tabular}

Table 6. Frequency of different parameters of LVH presence in men and women of both non-indigenous and indigenous nationality witCG data.

\begin{tabular}{|c|c|c|c|c|c|c|c|}
\hline \multirow{3}{*}{$\begin{array}{l}\text { ECG criteria } \\
\text { of LVH }\end{array}$} & \multirow{3}{*}{$n$} & \multicolumn{4}{|c|}{ Coincidences } & \multirow{3}{*}{$\chi^{2}$} & \multirow{3}{*}{$p$} \\
\hline & & \multicolumn{2}{|c|}{ no } & \multicolumn{2}{|c|}{ yes } & & \\
\hline & & abs. & rel. \% & abs. & rel. $\%$ & & \\
\hline Sokolow-Lyon & 66 & 35 & 53.0 & \multirow{2}{*}{31} & 47.0 & \multirow{2}{*}{5.00} & \multirow{2}{*}{$=0.023$} \\
\hline Cornell voltage & 124 & 93 & 75.0 & & 25.0 & & \\
\hline
\end{tabular}

bined criteria of Sokolow-Lyon with Cornell voltage, we concluded that the first one more often indicates the presence of LVH $\left(\chi^{2}=5.00 ; p=0.023\right)$ (see Table 6). The results of analysis of coincidence and discrepancy frequency of ECG-criteria Sokolow-Lyon and Cornell voltage are presented in Table 7.

The expected occurrence frequency of coincidence of Sokolow-Lyon and Cornell voltage ECG-criteria, assuming that these signs are mutually independent, is $6.5 \%$ $(0.186 \times 0.350=0.0651=6.5 \%)$ against the actual frequency of occurrence which is $8.8 \%$ that indirectly points to a really not very high correlation between these criteria $(r s=0.12, p=0.023$ ). The frequency of occurrence of discrepancies of ECG-criteria Sokolow-Lyon and Cornell voltage reached $36.2 \%(36.2=26.3+9.9)$ in the total group (354). As to the frequency of occurrence ofcoincidences, it was $63.9 \%(63.9=55.1+8.8)$. ECG signs of LVH Cornell voltage criteria occurs almost two times often than Sokolow-Lyon criteria $(35.0 \%$ and $18.6 \%$ respectively). It can be concluded that Cornell voltage criteria overestimates the true incidence of left ventricular hypertrophy, and Sokolow-Lyon is proved to be more informative.

Combination of Sokolow-Lyon $(n=66)$ and HuebnerUngerleider criteria $(n=12)$ in the total group of patients $(n=354)$ appeared only in three $(0.8 \%)$ cases. There was not observed any correlation between those two criteria $\left(\chi^{2}=0.04, p>0.10\right)$. The closest coincidence was observed between Cornell voltage and Huebner-Ungerleider criteria. There were 9 coincidences - with ECG signs in 12 people, establishedby Huebner-Ungerleider criterion, and in 124 people using Cornell voltage criterion
Table 7. Results of ECG-criteria of LVH (Sokolow-Lyon and Cornell voltage) in group of non-indigenous and indigenous patients (354) with CHD aged 60 and over.

\begin{tabular}{|c|c|c|c|c|c|c|}
\hline \multirow{3}{*}{$\begin{array}{c}\text { ECG-criteria } \\
\text { Cornell } \\
\text { voltage }\end{array}$} & \multirow{3}{*}{ abs. } & \multirow{3}{*}{ rel. \% } & \multicolumn{4}{|c|}{ ECG-criteria Sokolow-Lyon } \\
\hline & & & \multicolumn{2}{|c|}{ Absent $(n=288)$} & \multicolumn{2}{|c|}{ Present $(n=66)$} \\
\hline & & & abs. & rel. \% & abs. & rel. \% \\
\hline Absent & 230 & 65.0 & 195 & 55.1 & 35 & 9.9 \\
\hline Present & 124 & 35.0 & 93 & 26.3 & 31 & 8.8 \\
\hline Total & 354 & 100.0 & 288 & 81.4 & 66 & 18.6 \\
\hline
\end{tabular}

(75.0\% and $7.3 \%$ accordingly, $n=354)\left(\chi^{2}=7.00, p=\right.$ $0.008)$. A weak tendency was revealed in the group of Yakut people, indicating on a slightly more high informative value of Sokolow-Lyon criterion than Cornell voltage $\left(\chi^{2}=2.69, p=0.097\right)$. Combination of Cornell voltage and Huebner-Ungerleider criteria confirmed its efficiency in the group of Yakuts, where out of 6 patients, who were revieled by Huebner-Ungerleider criterion, 5 of them had coincidence with Cornell voltage criterion ( $n$ $=76)\left(\chi^{2}=3.81, p=0.048\right)$.

\section{DISCUSSION}

Ethnic distinctions in the frequency of $\mathrm{AH}$ occurrence were studied in a number of studies. Thus, comparatively low prevalence of arterial hypertension more often occurs among native citizenscompared to non-aboriginal population [10-14] of Russia: West Siberia-shors (Mountain Shoria), khanty (Khanty-Mansiysk), East Siberia - buryats (Baikal region, Republic of Buryatia). In recent years there is a tendency to increase the proportion of people with high blood pressure among indigenous population [15-17]. Probably it can be explained by changes made in lifestyles and disruption in peculiarity of national nutrition. The revealed increase of isolated systolic hypertension with age in the studied population, regardless of ethnicity, age and gender, is consistent with data from other literature sources [18,19], and this phenomenon is associated with a progressive growth in aortic stiffness $[20,21]$. The level of SBP increases with age herewith the role of $\mathrm{AH}$ as a risk factorfor long-livers probably higher than elderly patients that requires special attention to secondary prevention.

According to epidemiological studies, left ventricular hypertrophy, which is revealed by the method of ECG, is prognostically important predictor of cardiovascular events and mortality $[22,23]$. The method has a low sensitivity in terms of identifying left ventricular hypertrophy. Nevertheless, hypertrophy,established by SokolowLyon or Cornell voltagecriterion index, is an independent predictor of cardiovascular events [24].

The obtained data are confirmed in the works of other authors [25]. According to several researchers [26,27], 
Sokolow-Lyon criterion is not informative for patients having overweight. As for Cornell voltage criterion, the most important parameter for obese men is the S-wave amplitude in the precordial leads V3, for womenR-wave amplitude in AVL.

In the surveyed by us group of patients women were tend to have excessive body mass $(p<0.001)$. Men had less body mass index (BMI) than woman did and corresponded to the gradation of excessive body mass. According to our data, Cornell voltage criterion is less specific in regard to BMI and is registered more often in the group of patients with excessive body mass than Sokolow-Lyon criterion. Similar results were also obtained earlier by other authors [28]. As per data of M. M. Saltikova [27], excessive body mass and obesity contribute to change position of the diaphragm that in turn leads to the rotation and displacement of the heart and affects the amplitude voltage parameters-ECG LVH. Moreover, in her opinion, for women, who are overweight, change in voltage parameters in lead V3 depends on the accuracy of localization of the electrode $\mathrm{C} 3$ and its displacement to the right or below can bring to significant overestimation of the relevant voltage parameters of LVH.

\section{CONCLUSIONS}

1) Blood pressure increases with age while frequency of revealing of isolated systolic hypertension stays high in both ethnic groups. Prognostically adverse factors regarding the development of coronary heart disease are tendencies to more severe hypertension and to higher levels of diastolic blood pressure. The evidence of the importance of strengthening hypertension as a risk factor for development of coronary heart disease in nonindigenous patients is blood pressure and age relationship, thus, the more their age, the higher the blood pressure.

2) It is noted that the Cornell voltage criterion in the establishment of ECG signs is with a lower specificity of LVH than Sokolow-Lyon criteria with its significantly higher occurrence. The ECG signs of LVH for men are observed more often by Sokolow-Lyon criteria while it is the Cornell voltage criterion for women. The strongest correlation is found between the presence of LVH and combinations of Cornell voltage and Huebner-Ungerleider criteria, Sokolow-Lyon and Cornell voltage criteria.

\section{REFERENCES}

[1] (2012) World Health Statistics, Geneva.

[2] Demographic Yearbook of Russia (2010) Russian Statistics.

[3] Sukneva, S.A. (2009) Mortality rate in the Republic of Sakha (Yakutia). Statistical Issues, 8, 50-55.
[4] Ivanov, K., Klimova, T. and Kornileva, I.V. (2012) The dynamics of the effectiveness of treatment of hypertension in Yakutia. Cardio Somatica, 4, 48-51.

[5] Jackson, R., Wells, S. and Rodgers, A. (2008) Will screening individuals at high risk of cardiovascular events deliver large benefits? Yes. BMJ, 337, 1371.

[6] Nikitin, P., Kazakova, G., Zykov, V., et al. (1991) Features of of hypertension in the alien population of Chukotka. Cardiology, 9, 68-71. doi:10.1136/bmj.a1371

[7] Barnes, P.M., Adams, P.F. and Powell-Griner, E. (2008) Health characteristics of the Asian adult population: United States, 2004-2006. Advance Data, 394, 1-22.

[8] Reeves, T.J. and Bennet, C.E. (2004) We the people: Asians in the United State-Census 2000 special reports (CENSR-17). US Bureau of Census, Washington, DC.

[9] Rosamond, W., Flegal, K. and Friday, G. et al. (2007) Heart disease and stroke statistics - 2007 update: A report from the American Heart Association Statistics Committee and Stroke Statistics Subcommittee. Circulation, 115, 69-171. doi:10.1161/CIRCULATIONAHA.106.179918

[10] Donirova, O.S. (2009) Combined atherosclerotic lesions of coronary arteries and arteries of the lower extremities in the Republic of Buryatia. Synopsis, Irkutsk.

[11] Kireeva, V.V. and Orlova, G.M. (2006) Clinical and prognostic significance of coronary heart disease risk factors in different ethnic groups of Baikal region. Siberian $\mathrm{Me}$ dical Journal, 4, 34-36.

[12] Malakshinova, Z.H. (1997) Coronary heart disease and risk factors among native and non-native population of Ulan-Ude based on cross-sectional and prospective study. Synopsis, Saint Petersburg.

[13] Ogarkov, M.Y., Barbarash, O.L., Polikutina, O.M., et al. (2003) The prevalence of coronary heart disease in indigenous and non-indigenous population of Mountain Shoria. Bulletin of the SB RAMS, 108, 58-63.

[14] Shestakova, G.N. (2004) The cardiovascular and respiratory systems of the indigenous population of Khanty the North Tyumen region. Synopsis, Tyumen.

[15] Gyrkolkau, L.A. and Sherbakova, L.V. (2010) Blood pressure levels and the frequency of hypertension in Chukotka natives. Bulletin of the SB RAMS, 30, 58-63.

[16] Kornileva, I.V., Ivanov, K.I., Alexeeva, E. Yu., et al. (2003) The prevalence of hypertension in the Republic of Sakha (Yakutia). Hypertension, 5, 182-184.

[17] Mulerova, T.A., Filimonov, S.N., Onishchenko, E.G., et al. (2012) Arterial hypertension and lipid metabolism in tubularov and non-indigenous the Republic of Altai. Basic Research, 8, 372-376.

[18] Burt, V.L., Whelton, P., Roccella, E.J., et al. (1995) Prevalence of hypertension in the US adult population: Results from the Third National Health and Nutrition Examination Survey, 1988-1991. Hypertension, 25, 305-313.

[19] Lloyd-Jones, D., Adams, R., Carnethon, M., et al. (2009) Heart disease and stroke statistics - 2009 update: A report from the American Heart Association Statistics Committee and Stroke Statistics Subcommittee. Circulation, 119, 121-181. 
[20] Dzizinsky, A.A. and Protasov, K.V. (2008) Isolated systolic hypertension: Pathogenesis, diagnosis, treatment. Publishing Department, Irkutsk.

[21] Staessen, J., Amery, A. and Fagard, R. (1990) Isolated systolic hypertension in the elderly. Journal of Hypertension, 8, 393-405.

[22] Kannel, W.B., Gordon, T. and Offutt, D. (1969) Left ventricular hypertrophy by electrocardiogram. Prevalence, incidence, and mortality in the Framingham Study. Annals of Internal Medicine, 71, 89-105.

[23] Verdecchia, P., Schillaci, G., Borgioni, C., et al. (1998) Prognostic value of a new electrocardiographic method for diagnosis of left ventricular hypertrophy in essential hypertension. Journal of the American College of Cardiology, 31, 383-390.

[24] Levy, D., Salomon, M., D‘Agostino, R.B., et al. (1994) Prognostic implications of baseline electrocardiographic

\section{Note}

SBP-systolic blood pressure;

$\mathrm{DBP}$ - diastolic blood pressure;

CHD—coronary heart disease; features and their serial changes in subjects with left ventricular hypertrophy. Circulation, 90, 1786-1793. doi:10.1161/01.CIR.90.4.1786

[25] Efimova, V.P. (2008) Capabilities to monitor the evolution of electrocardiographic left ventricular hypertrophy. Synopsis, Moskow.

[26] Gabrusenko, S.A. (2004) Hypertrophic cardiomyopathy: Current problems. Consilium Medicum, 6, 350-355.

[27] Saltykova, M.M., Muromtseva, G.A., Baum, O., et al. (2008) The influence of gender on informational content of different electrocardiographic criteria for left ventricular hypertrophy in patients with excessive body mass. Cardiology, 48, 23-25.

[28] Saltykova, M.M., Ryabykina, G.V., Oshchepkova, E.V., et al. (2006) Electrocardiographic diagnosis of left ventricular hypertrophy in patients with hypertension and overweight. Therapeutic Archives, 12, 40-45.

$\mathrm{AH}-$ arterial hypertension;

ECG-Electrocardiography;

LVH-left ventricular hypertrophy;

BMI—body mass index. 